\title{
Thermal Shock Corrosion of Valve Steels Utilized in Automobile Industry
}

\author{
Z. Grzesik • G. Smoła • K. Adamaszek • Z. Jurasz • \\ S. Mrowec
}

Received: 20 June 2012/Revised: 9 January 2013/Published online: 3 February 2013

(C) The Author(s) 2013. This article is published with open access at Springerlink.com

\begin{abstract}
The high-temperature corrosion behavior of four valve steels (X33CrNiMn23-8, X50CrMnNiNbN21-9, X53CrMnNiN20-8 and X55CrMnNiN208 ) in combustion gases of fuel oil, containing different concentrations of bio-components ( 5 and $10 \mathrm{wt} \%$ ) has been studied under thermal shock conditions. It was found that the addition of bio-components decreased the corrosion resistance of steels investigated. It was also found that the $\mathrm{X} 33 \mathrm{CrNiMn} 23-8$ steel containing the highest chromium concentration, behaved in the investigated atmospheres much better than three remaining steels due to the formation of highly protective chromia scale.
\end{abstract}

Keywords Steel $\cdot$ Thermal cycling $\cdot$ High temperature corrosion

\section{Introduction}

Four chromium-nickel steels are being generally utilized in the production of valves in automobile engines. It has been found earlier that under isothermal conditions, the corrosion resistance of these materials in oxidizing atmospheres at temperatures 873-1,273 K depends first of all on chromium concentration [1-3]. The higher, namely, the concentration of chromium, the better is the corrosion resistance of these steels. Thus, the X33CrNiMn23-8 steel, containing the highest chromium concentration, shows good oxidation resistance, due to selective oxidation of chromium and the formation of highly protective chromia $\left(\mathrm{Cr}_{2} \mathrm{O}_{3}\right)$ scale. In the case

Z. Grzesik ( ()$\cdot$ G. Smoła $\cdot$ S. Mrowec

Department of Physical Chemistry and Modelling, Faculty of Materials Science and Ceramics, AGH

University of Science and Technology, al. A. Mickiewicza 30, 30-059 Krakow, Poland

e-mail: grzesik@agh.edu.pl 
of three other steels (X50CrMnNiNbN21-9, X53CrMnNiN20-8 and X55CrMnNiN20-8) the concentration of chromium is too low for its selective oxidation. Consequently, the scale is heterogeneous, showing worse protective properties.

The discussed valve steels are working in very severe conditions due to rather high temperatures and in particular due to sudden temperature changes, described in the literature as thermal shocks. It is well known that in this case, high thermal stresses are developed in the scale-substrate system, due to different thermal expansion coefficients of both materials $[4,5]$. As a consequence, during heating and cooling of the engine, cracking and spalling of the scale is observed, considerably lowering the corrosion resistance of a given material [4-8]. Under those conditions the scale adherence to the substrate surface constitute the most important problem, determining in the first place the corrosion resistance of the material.

In last few years fuel oils, utilized in automobile industry contain biocomponents (fatty acid methyl esters-FAME) [9], influencing negatively the corrosion resistance of engine valves [10-16]. Thus, the present paper is an attempt to get new information on the influence of bio-component additions to fuel oil on corrosion resistance of valve steels in the atmosphere of combustion gasses under thermal shock conditions. During last 10 years the concentration of bio-components in fuel oil in EU countries is continuously increasing and nowadays is generally equal to about $5 \mathrm{wt} \%$ (fuel oil B5), but it is decided that in the next future, this concentration will increase up to $10 \mathrm{wt} \%$ (fuel oil B10) [9]. However, the presence of bio-components in the fuel oil is dangerous from corrosion point of view, because of high aggressive properties of their combustion products [10-16]. This is the reason, why the results of corrosion behavior under thermal shock conditions of four valve steels being used in the production of valve engines have been reported in the present paper.

\section{Materials and Experimental Procedures}

Chemical compositions of the studied valve steels and properties of fuel oil, containing different concentrations of bio-components (5 and $10 \mathrm{wt} \%)$ are summarized in Tables 1 and 2, respectively.

Table 1 The chemical compositions (wt\%) of X33CrNiMn23-8, X50CrMnNiNbN21-9, X53CrMnNiN20-8 and X55CrMnNiN20-8 valve steels

\begin{tabular}{lcccccccccccc}
\hline Type of steel & $\mathrm{C}$ & $\mathrm{Mn}$ & $\mathrm{Si}$ & $\mathrm{Cr}$ & $\mathrm{Ni}$ & $\mathrm{N}$ & $\mathrm{W}$ & $\mathrm{Nb}$ & $\mathrm{S}$ & $\mathrm{P}$ & $\mathrm{Mo}$ & $\mathrm{Fe}$ \\
\hline X33CrNiMn23-8 & 0.35 & 3.3 & 0.63 & 23.4 & 7.8 & 0.28 & 0.02 & - & $<0.005$ & 0.014 & 0.11 & Bal. \\
X50CrMnNiNbN21-9 & 0.54 & 7.61 & 0.30 & 19.88 & 3.64 & 0.44 & 0.86 & 2.05 & 0.001 & 0.031 & - & Bal. \\
X53CrMnNiN20-8 & 0.53 & 10.3 & 0.30 & 20.5 & 4.1 & 0.41 & - & - & $<0.005$ & 0.04 & 0.12 & Bal. \\
X55CrMnNiN20-8 & 0.55 & 8.18 & 0.17 & 20.0 & 2.3 & 0.38 & - & - & $<0.005$ & 0.03 & 0.11 & Bal. \\
\hline
\end{tabular}


Table 2 Properties of diesel fuels

\begin{tabular}{lllll}
\hline Property & Fuel oil B5 & Fuel oil B10 & EN standard & Specification limit \\
\hline Density at $15{ }^{\circ} \mathrm{C}\left(\mathrm{kg} / \mathrm{m}^{3}\right)$ & 832.0 & 838.0 & EN ISO 12185 & $820-845$ \\
Ignition temperature $\left({ }^{\circ} \mathrm{C}\right)$ & 61.0 & 69.5 & EN ISO 2719 & $>55$ \\
Cetane number & 55.0 & 51.4 & EN ISO 5165 & $>51$ \\
Water content $(\mathrm{mg} / \mathrm{kg})$ & 26 & 150 & EN ISO 12937 & $<200$ \\
Sulphur content $(\mathrm{mg} / \mathrm{kg})$ & 4.9 & 8.1 & EN ISO 20846 & $<10$ \\
Solid impurities $(\mathrm{mg} / \mathrm{kg})$ & 6.0 & 9.0 & EN ISO 12637 & $<24$ \\
Residue after incineration $(\mathrm{mg} / \mathrm{kg})$ & 0.001 & $<0.001$ & EN ISO 6245 & $<0.01$ \\
CCFP $\left({ }^{\circ} \mathrm{C}\right)$ & -24 & -29 & EN 116 & $<-20$ \\
Fractional composition & & & & $<65$ \\
Up to $250{ }^{\circ} \mathrm{C}(\%)$ & 36.7 & 32.2 & EN ISO 3405 & $>85$ \\
Up to 350 ${ }^{\circ} \mathrm{C}(\%)$ & 95.4 & 95.8 & & $<360$ \\
$\begin{array}{l}\text { Temperature, at which } 95 \mathrm{vol} \% \\
\text { of fuel distillates }\left({ }^{\circ} \mathrm{C}\right)\end{array}$ & 348.5 & 347.0 & & \\
\begin{tabular}{l} 
FAME content $(\%)$ \\
\hline
\end{tabular} & 4.9 & 9.5 & EN 14078 & $5 \pm 0.5 / 10 \pm 1$ \\
\hline
\end{tabular}

The samples for corrosion experiments have been obtained from rods of steels with diameter of $20 \mathrm{~mm}$ and the thickness of approximately $1 \mathrm{~mm}$. These discshaped samples were grinded with emery papers (up $800 \mathrm{SiC}$ ) and finally polished using diamond pastes to obtain mirror-like surfaces.

The corrosion tests have been carried out using gravimetric method, consisting in rapid heating of a given sample from room temperature up to $973 \mathrm{~K}$ (or 1,173 K) and after treating it at this temperature during $2 \mathrm{~h}$, subsequently cooling down rapidly (quenching) to room temperature. The duration of heating time was approximately equal to $1 \mathrm{~min}$. The cooling time, in turn (quenching), proceeded in combustion gases during about 2 min. These experiments consisted in determining the mass changes of corroded samples as a function of number of thermal shocks. Two different temperatures ( 973 and $1,173 \mathrm{~K}$ ) of corrosion tests have been chosen to simulate the temperature range, observed in diesel engines. The scheme of setup used in corrosion tests is presented in Fig. 1. Figure 2, in turn, illustrates the photographs of the discussed setup together with an engine, on which furnace is located in two different positions, corresponding to heating and cooling periods.

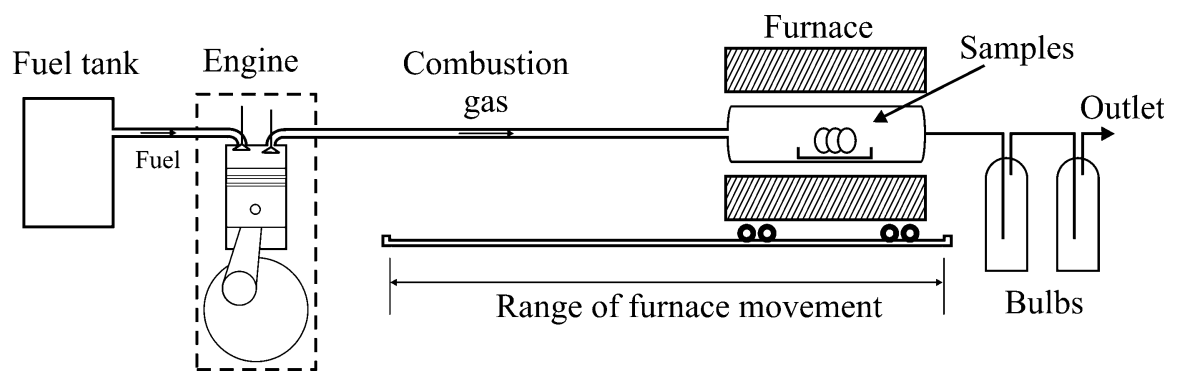

Fig. 1 The scheme of setup used in corrosion tests 

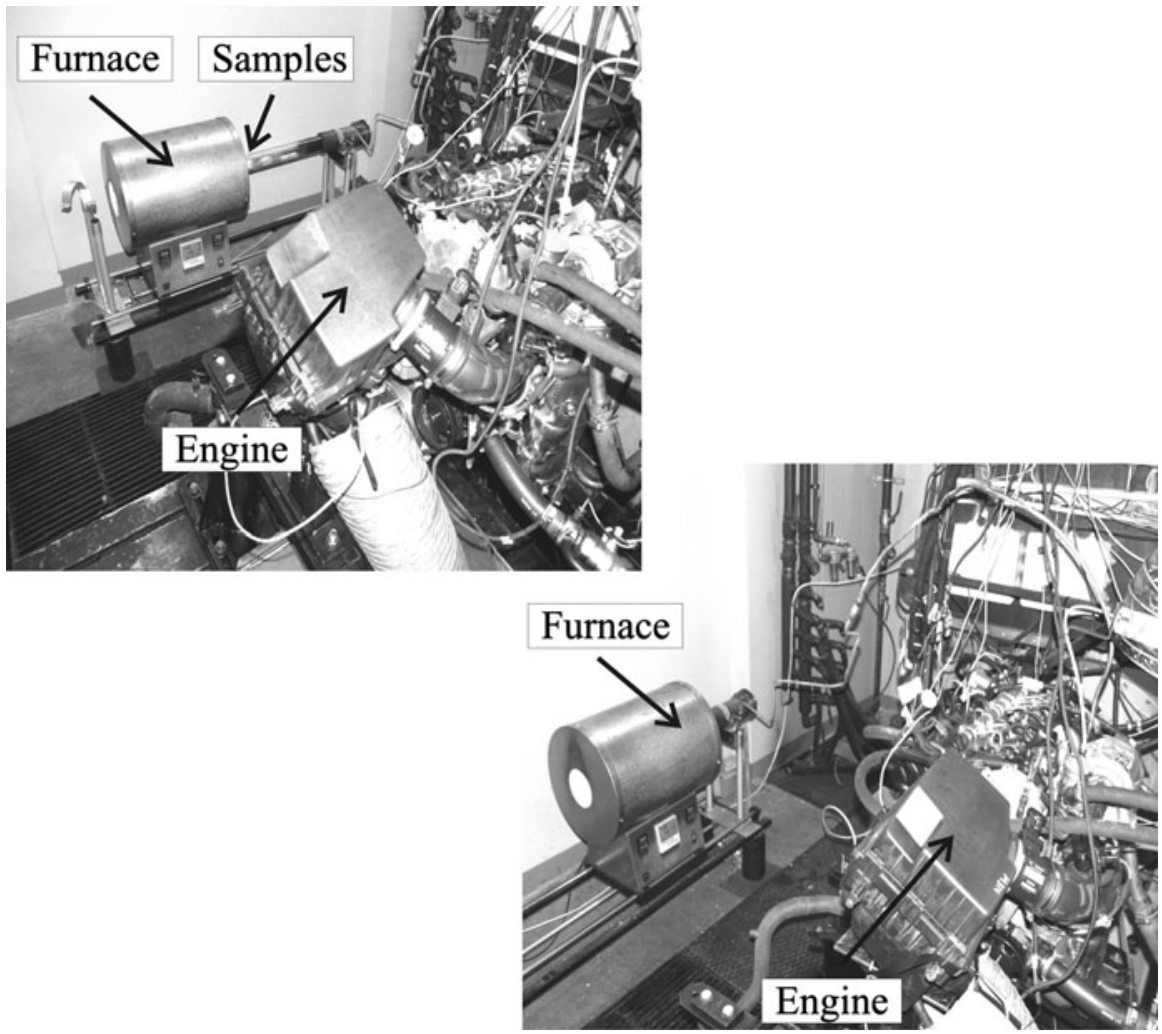

Fig. 2 The photographs of the engine test house containing the setup with an engine, illustrating two different positions of furnace, corresponding to heating and cooling periods

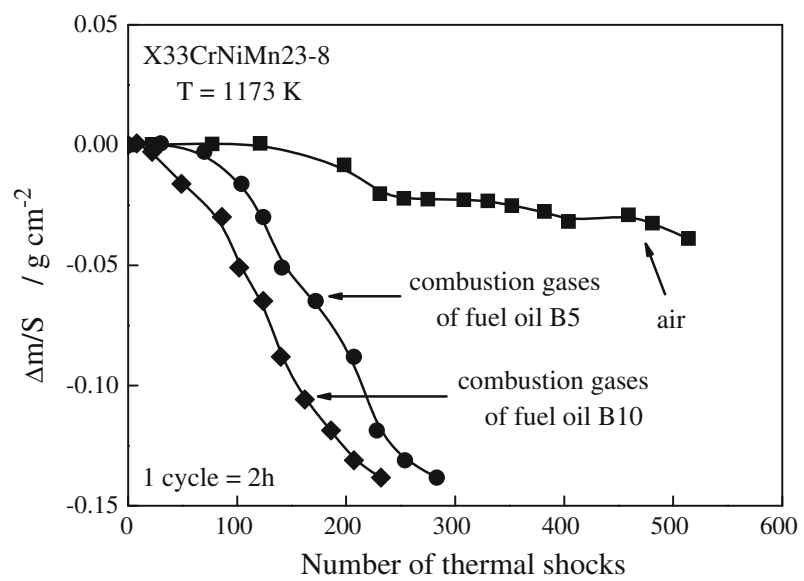

Fig. 3 The results of thermal shocks of the X33CrNiMn23-8 steel, investigated in combustion gases of fuel oil B5 and B10 at $1,173 \mathrm{~K}$ on the background of analogous results obtained in pure air $(\Delta \mathrm{m} / \mathrm{S}$ weight changes of the corroded samples per unit surface area) 
These experiments have been performed in combustion gases of diesel engine installed in engine test house, containing the combustion products of biocomponents (FAME) added in different amounts (5 and $10 \mathrm{wt} \%$ ). The number of heating tests, corresponding up to $600 \mathrm{~h}$ of valve works, has been chosen in order to simulate the standard time procedure of investigation of material quality of engines, utilized in automobile industry.

The interpretation of corrosion tests under discussion was as follows. If the corroded sample looses gradually its mass with successive thermal shocks, it means

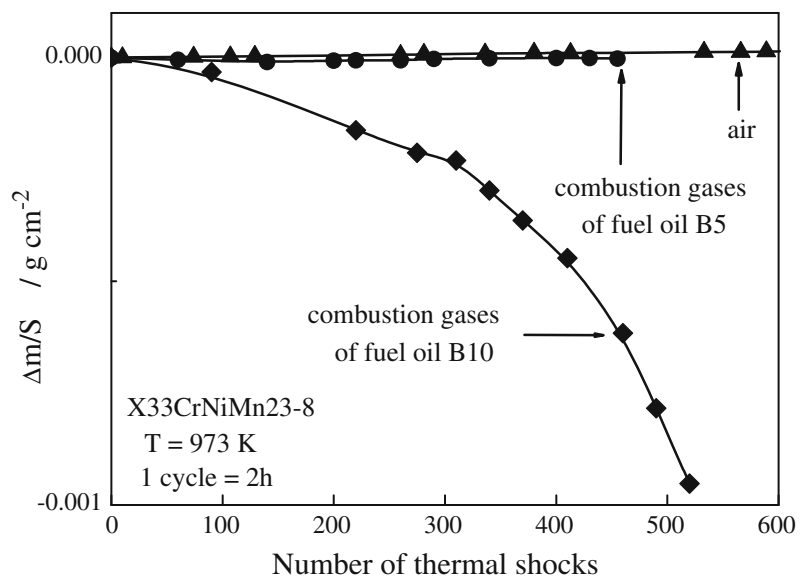

Fig. 4 The results of thermal shocks of the X33CrNiMn23-8 steel, investigated in combustion gases of fuel oil B5 and B10 at $973 \mathrm{~K}$ on the background of analogous results obtained in pure air $(\Delta \mathrm{m} / \mathrm{S}$ weight changes of the corroded samples per unit surface area)

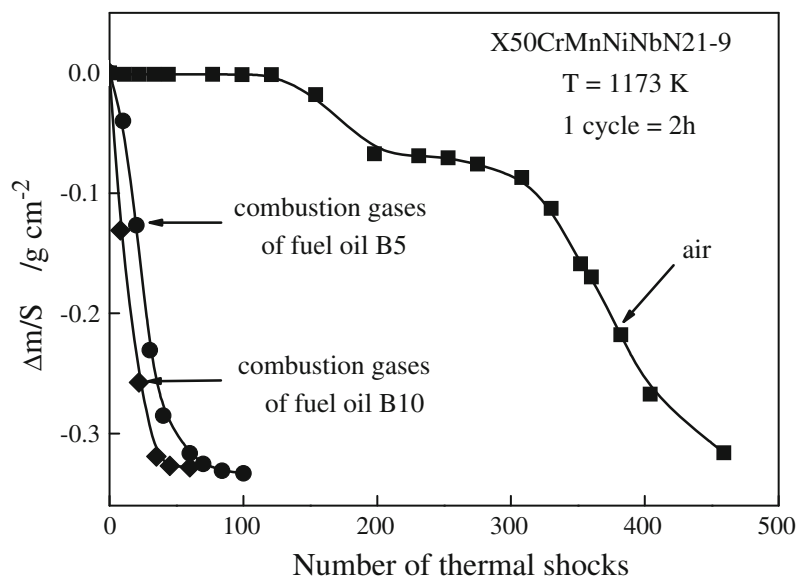

Fig. 5 The results of thermal shocks of the X50CrMnNiNbN21-9 steel, investigated in combustion gases of fuel oil B5 and B10 at $1,173 \mathrm{~K}$ on the background of analogous results obtained in pure air $(\Delta \mathrm{m} / \mathrm{S}$ weight changes of the corroded samples per unit surface area) 
that the scale cracks and spall off from the surface of the material due to thermal stresses. It follows from these experiments that the higher are mass losses of the sample as a function of a number of thermal shocks, the worse is the scale adherence and consequently, protective properties of the scale. On the other hand, if the mass of the sample does not change virtually with the number of shocks, it means that in spite of thermal stresses the scale does not crack and spall off from the substrate surface, due to its very good adherence and consequently it protects satisfactorily the material against high temperature corrosion.

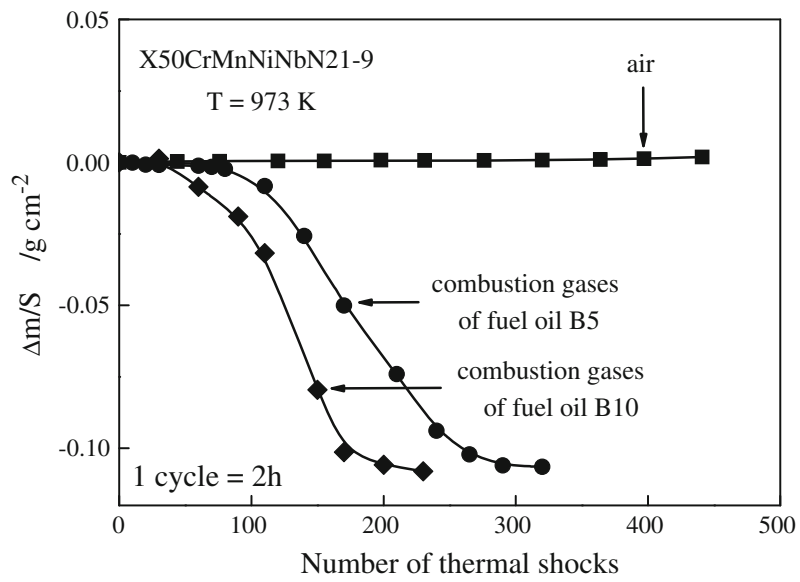

Fig. 6 The results of thermal shocks of the X50CrMnNiNbN21-9 steel, investigated in combustion gases of fuel oil B5 and B10 at $973 \mathrm{~K}$ on the background of analogous results obtained in pure air $(\Delta \mathrm{m} / \mathrm{S}$ weight changes of the corroded samples per unit surface area)

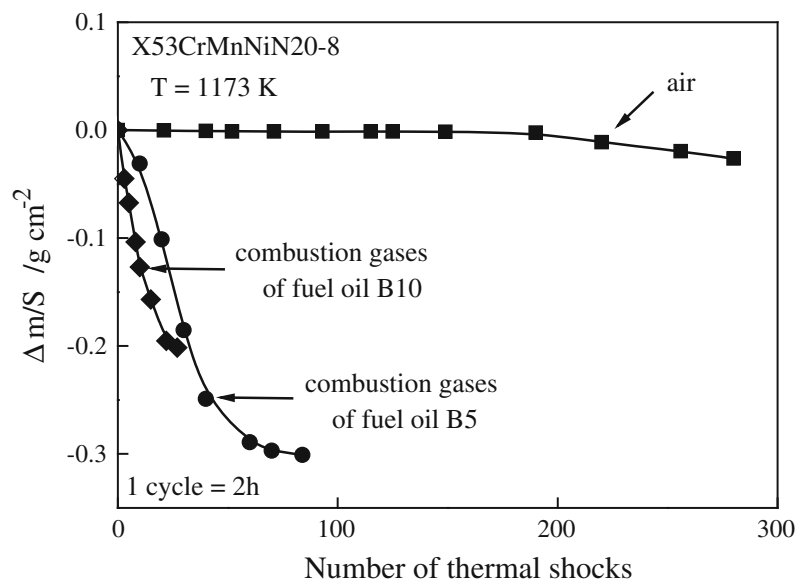

Fig. 7 The results of thermal shocks of the X53CrMnNiN20-8 steel, investigated in combustion gases of fuel oil B5 and B10 at $1,173 \mathrm{~K}$ on the background of analogous results obtained in pure air $(\Delta \mathrm{m} / \mathrm{S}-$ weight changes of the corroded samples per unit surface area) 


\section{Results and Discussion}

The diagram presented in Fig. 3 illustrates the results of corrosion progress under thermal shock conditions of the X33CrNiMn23-8 steel, obtained in two different atmospheres (i.e. in combustion gases of oil fuel B5 and B10) at 1,173 $\mathrm{K}$ on the background of analogous results obtained in pure air [9]. As can be seen, the corroded sample in pure air does not virtually change its mass during thermal shocks, indicating that under these conditions very thin scale does not crack and spall off, showing thus excellent adherence to the substrate. Combustion gasses, on the other hand, containing different concentrations of combustion products of bio-

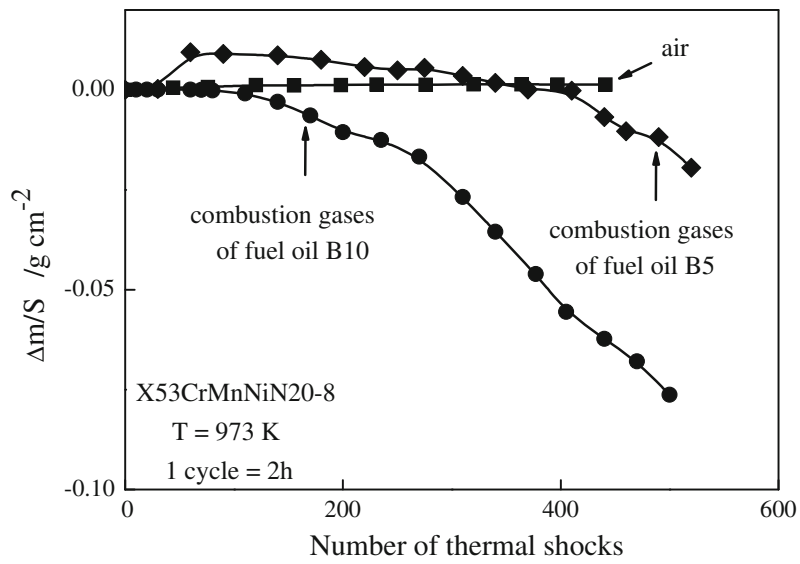

Fig. 8 The results of thermal shocks of the X53CrMnNiN20-8 steel, investigated in combustion gases of fuel oil B5 and B10 at $973 \mathrm{~K}$ on the background of analogous results obtained in pure air $(\Delta \mathrm{m} / \mathrm{S}$ weight changes of the corroded samples per unit surface area)

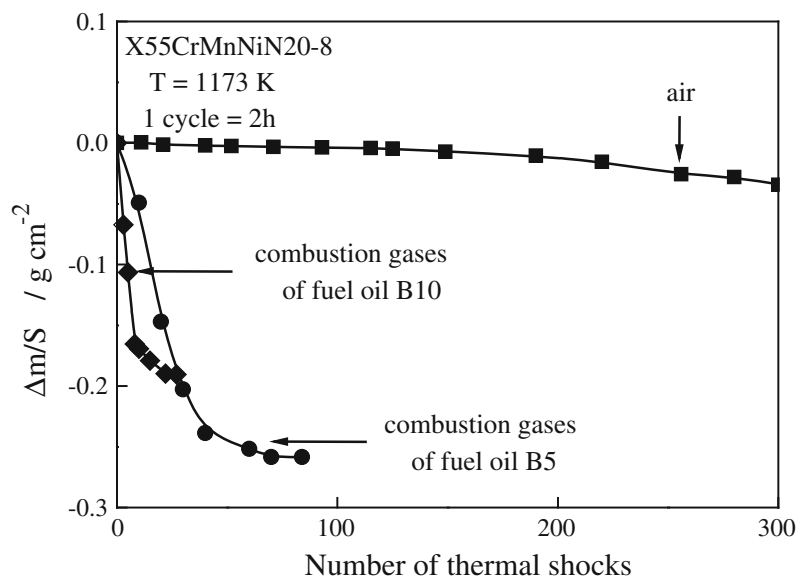

Fig. 9 The results of thermal shocks of the X55CrMnNiN20-8 steel, investigated in combustion gases of fuel oil B5 and B10 at $1,173 \mathrm{~K}$ on the background of analogous results obtained in pure air $(\Delta \mathrm{m} / \mathrm{S}$ weight changes of the corroded samples per unit surface area) 
components show high aggressive properties, which increase with increasing content of bio-components in the fuel oil. This conclusion follows directly from rapid decrease of mass of tested samples with increasing number of thermal shocks, clearly indicating that in these atmospheres the scales cracks and spall off from sample surface, showing thus much worse adherence to the substrate than that observed in pure oxygen atmospheres. The situation is slightly different at lower temperature $(973 \mathrm{~K})$, as shown in Fig. 4. It follows from this diagram that the presence of $5 \mathrm{wt} \%$ of bio-components (B5) does not influence virtually the corrosion behavior of the X33CrNiMn23-8 steel under thermal shock conditions. Higher concentration of bio-components $(10 \mathrm{wt} \%)$, on the other hand, is reflected in mass decrease of corroded sample as a function of number thermal shocks, clearly indicating that at this concentration of bio-component the scale spallation is observed.

Further six diagrams presented in Figs. 5, 6, 7, 8, 9 and 10 illustrate the behavior of remaining three steels under thermal shock conditions. From these diagrams it follows distinctly, that like in the case of the $\mathrm{X} 33 \mathrm{CrNiMn23-8}$ steel, the corrosion rate of three remaining steels increases both with temperature and concentration of bio-components. However, all these steels undergo much faster corrosion in combustion gases, as compared to oxygen atmosphere.

These differences are reflected in both, morphological structure and phase composition of scales. Figure 11 illustrates the macroscopic pictures of sample surfaces of all four steels after corrosion tests in discussed atmospheres. It follows from this figure that in agreement with corrosion tests, the adherence of the scale to the substrate in the case of all four steels corroded in combustion gases is considerable worse than in pure air atmosphere. However, in the case of the $\mathrm{X} 33 \mathrm{CrNiMn} 23-8$ steel, the degree of scale degradation is less visible. It may be then concluded that the increase of the concentration of bio-components in fuel oil may

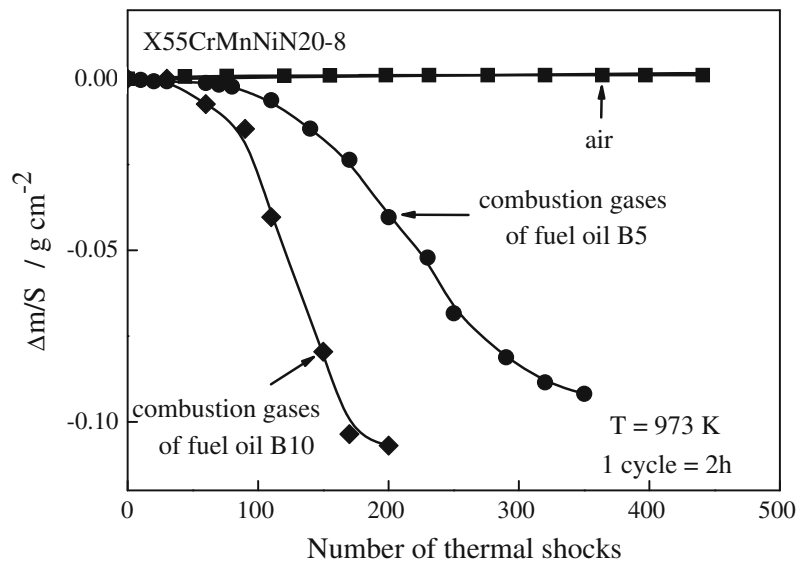

Fig. 10 The results of thermal shocks of the X55CrMnNiN20-8 steel, investigated in combustion gases of fuel oil B5 and B10 at $973 \mathrm{~K}$ on the background of analogous results obtained in pure air $(\Delta \mathrm{m} / \mathrm{S}$ weight changes of the corroded samples per unit surface area) 

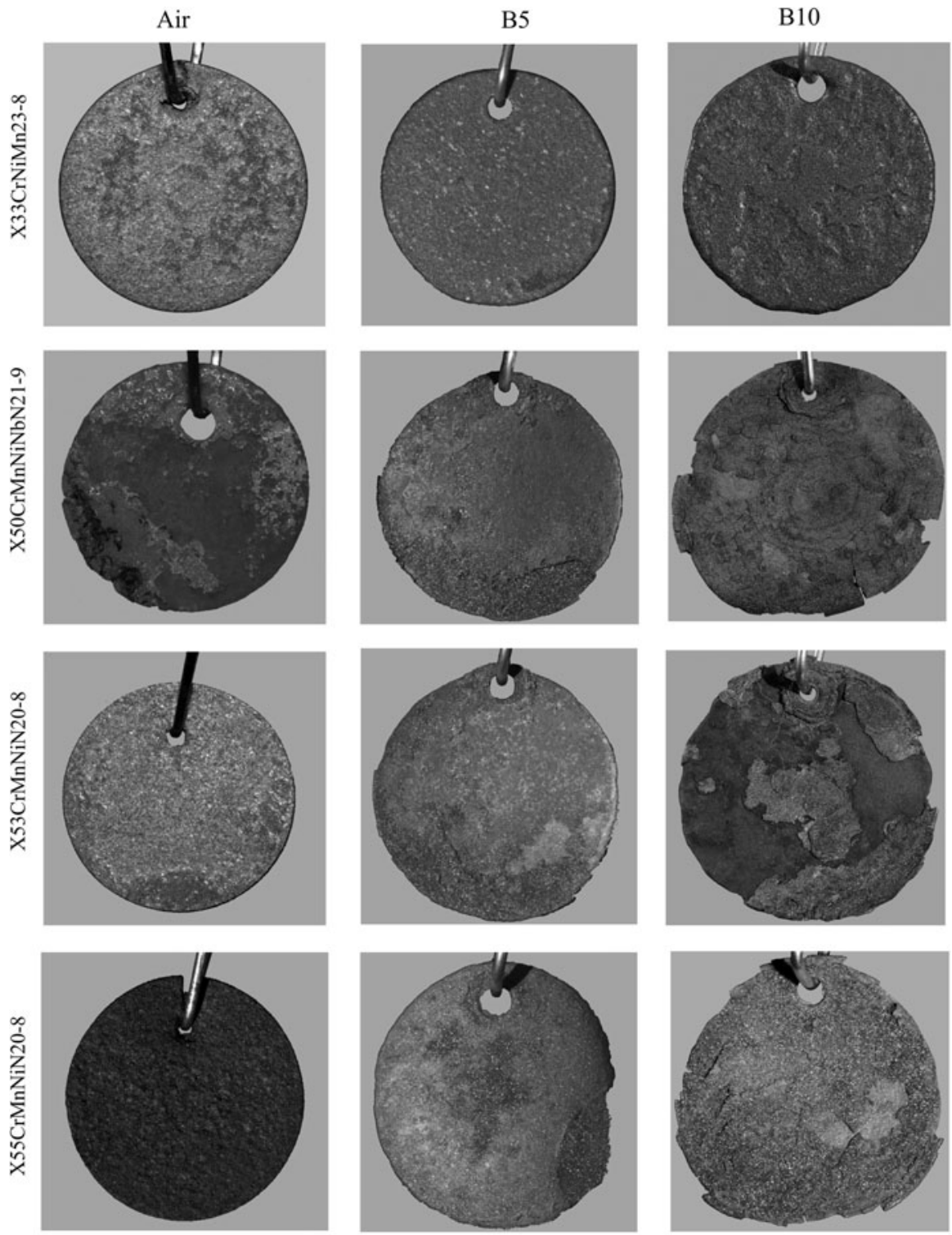

\section{$10 \mathrm{~mm}$}

Fig. 11 The macrophotographs of surfaces of valve steel samples under discussion after corrosion tests carried out in different atmospheres at $1,173 \mathrm{~K}$

create important problems in long-term life-time of automobile engines. These observations are also in agreement with X-ray diffraction data, presented in Figs. 12, 13, 14 and 15. From XRD data presented in Fig. 12 it follows, namely, that in early stages of corrosion of the $\mathrm{X} 33 \mathrm{CrNiMn} 23-8$ steel during initial 50 thermal 


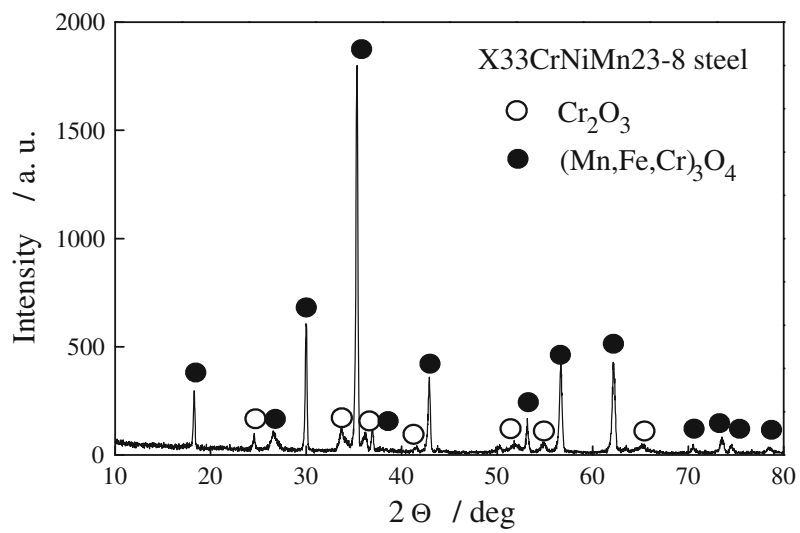

Fig. 12 X-ray diffraction patterns of the $\mathrm{X} 33 \mathrm{CrNiMn} 23-8$ steel sample surface after 50 thermal shocks in fuel oil $\mathrm{B} 5$ at $1,173 \mathrm{~K}$

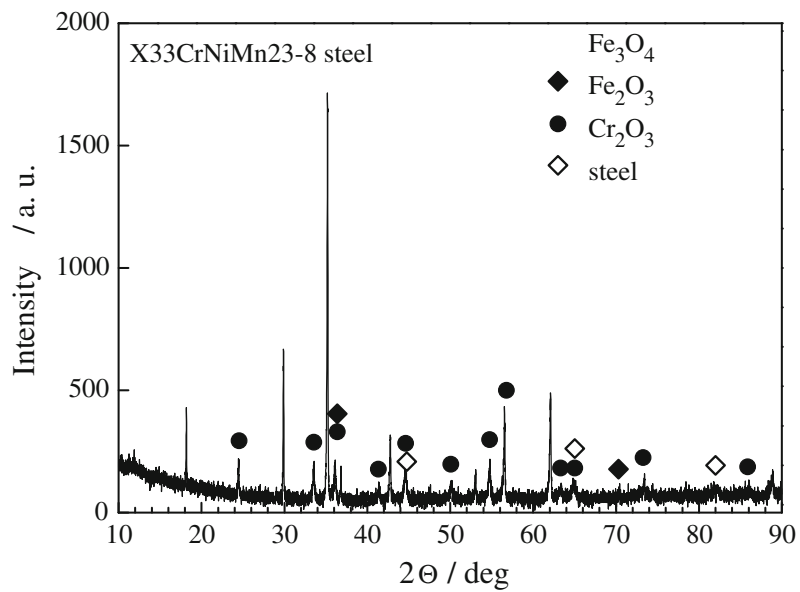

Fig. 13 X-ray diffraction patterns of the X33CrNiMn23-8 steel sample surface after 200 thermal shocks in fuel oil $\mathrm{B} 5$ at $1,173 \mathrm{~K}$

shocks, the scale is build mainly of chromium oxide, $\mathrm{Cr}_{2} \mathrm{O}_{3}$, with small spinel phase inclusions. In later stages (Fig. 13), on the other hand, reaching 500 thermal shocks, spinel phase is not detected at all, and on the surface of chromia scale thin layer of iron oxides $\left(\mathrm{Fe}_{3} \mathrm{O}_{4}\right.$ and $\left.\mathrm{Fe}_{2} \mathrm{O}_{3}\right)$ are observed. Different situation is observed in the case of three remaining steels with the lower chromium concentrations. From Fig. 14 it follows that in the case of the X50CrMnNiNbN21-9 steel, the scale in early stages of its formation is highly heterogeneous, containing a number of spinel phases, but not a separate chromia phase. In later stages of the reaction (Fig. 15), spinel phases gradually disappear and the scale is build from iron oxides $\left(\mathrm{Fe}_{3} \mathrm{O}_{4}\right.$ and $\mathrm{Fe}_{2} \mathrm{O}_{3}$ ), only. Analogous results have been obtained in the case of the X53CrMnNiN20-8 and X55CrMnNiN20-8 steels. 


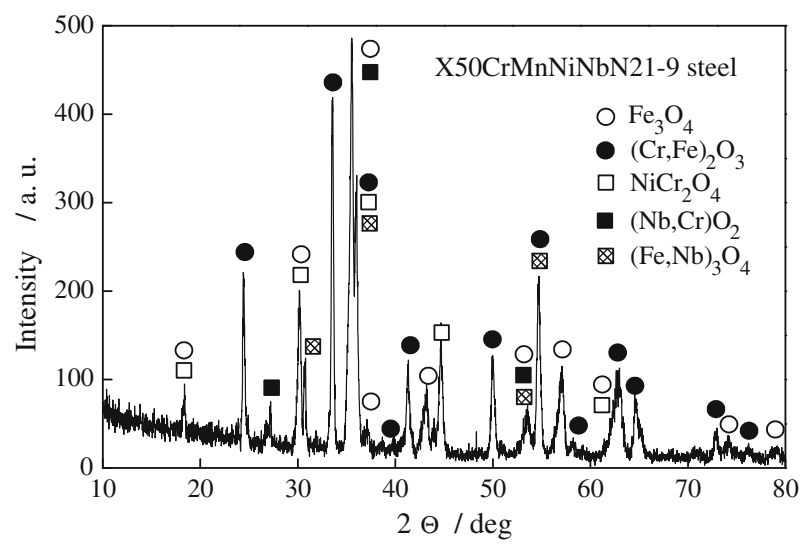

Fig. 14 X-ray diffraction patterns of the X50CrMnNiNbN21-9 steel sample surface after 20 thermal shocks in fuel oil $\mathrm{B} 5$ at $1,173 \mathrm{~K}$

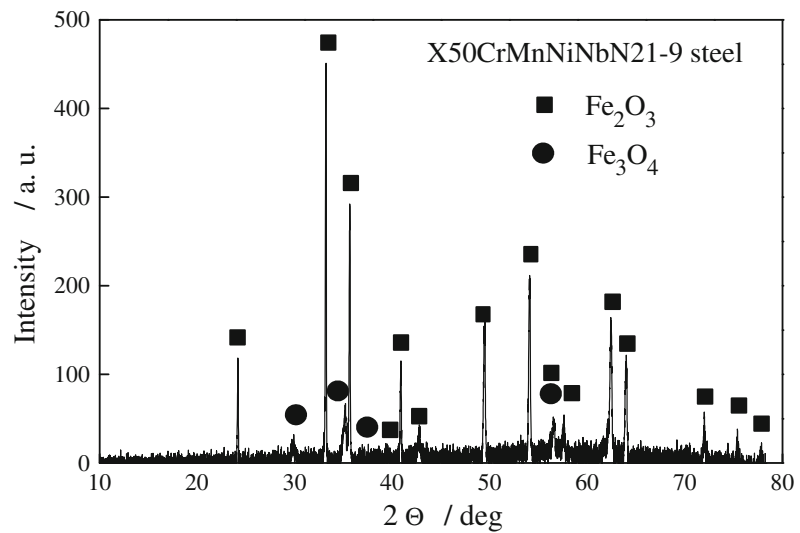

Fig. 15 X-ray diffraction patterns of the X50CrMnNiNbN21-9 steel sample surface after 50 thermal shocks in fuel oil B5 at $1,173 \mathrm{~K}$

The results described above strongly suggest that corrosion resistance of steels under investigations depends mainly on chromium concentration in the alloy. The X33CrNiMn23-8 steel, containing highest chromium concentration behaves, namely, much better than three remaining ones not only in pure air but also in combustion gasses, containing combustion products of bio-components. This difference results from the fact that the concentration of chromium in the $\mathrm{X} 33 \mathrm{CrNiMn} 23-8$ steel is high enough for selective oxidation of this metal and the formation of highly protective chromia scale, well adherent to the substrate. However, in combustion gases this chromium concentration is insufficient for the formation of completely compact chromia scale. Consequently, the corrosion rate of this material is higher than in purely oxidizing atmosphere, but much lower than those of three remaining steels with lower chromium concentration. It may be than concluded that in the future application of valve steels, the concentration of 
chromium in these materials should be even slightly higher than that in the X33CrNiMn23-8 steel.

\section{Conclusions}

One of the most important conclusions, following from the results described in the present paper consists in the demonstration that the addition of bio-components to the fuel oil increases the corrosion rate of steels utilized in valve production. It has been found also that the deteriorating effect of bio-components increases rapidly with increasing amount of these additions as well as with increasing temperature. As the combustion gases of fuel oil containing bio-components are a mixture of a number of compounds, showing different aggressive properties, the next step in this area of research should be the determination of the most aggressive compound of this mixture in order to find an appropriate inhibitor. This problem is a subject of current investigation in our laboratory.

The last but definitely not least conclusion is, that an improvement of corrosion resistance of valve steels could be obtained by increasing the chromium concentration in these materials and/or by addition of rare earth elements.

Acknowledgments This work was supported by The National Centre for Research and Development in Poland no. N R15 0013 06/2009.

Open Access This article is distributed under the terms of the Creative Commons Attribution License which permits any use, distribution, and reproduction in any medium, provided the original author(s) and the source are credited.

\section{References}

1. K. Adamaszek, Z. Jurasz, L. Swadzba, Z. Grzesik and S. Mrowec, High Temperature Materials and Processes 26, 115-122 (2007).

2. Z. Jurasz, K. Adamaszek, R. Janik, Z. Grzesik and S. Mrowec, Journal of Solid State Electrochemistry 13, 1709-1714 (2009).

3. Z. Grzesik, Z. Jurasz, K. Adamaszek, and S. Mrowec, High Temperature Materials and Process (in press) (2012).

4. S. Mrowec, and T. Weber, Scaling-Resistant Iron-Base Alloys in Modern Scaling-Resistant Materials (National Bureau of Standards and National Science Foundation, Washington D.C., 1982), p. 277.

5. P. Kofstad, Development of Stresses and Strains, Non-Protective Scales, Phase Boundary Reactions in High Temperature Corrosion (Elsevier Applied Science, London, 1988), p. 278.

6. D. Naumenko, L. Singheiser, and W. J. Quadakkers, in Proceedings on EFC Workshop (EFC, Frankfurt/Main 1999), p. 287.

7. M. Beukenberg, in Proceedings of Turbine Forum 2006, Advances Coatings for High Temperatures (Turbine Forum, Nice, 2006), April 26-28.

8. Z. Grzesik, S. Mrowec, Z. Jurasz and K. Adamaszek, High Temperature Materials and Processes 29, 35-45 (2010).

9. Directive 2003/30/EC of the European Parliament and of the Council of 8 May 2003, Official Journal of the European Union L 123, 43-46 (2003).

10. A. S. M. A. Haseeb, M. A. Fazal, M. I. Jahirul and H. H. Masjuki, Fuel 90, 922-931 (2011).

11. Z. W. Yu and X. L. Xu, Engineering Failure Analysis 13, 673-682 (2006). 
12. C. G. Scott, A. T. Riga and H. Hong, Wear 181-183, 485-494 (1995).

13. D. Schlager, C. Theiler and H. Kohn, Materials and Corrosion 53, 103-110 (2002).

14. M. Velliangiri and A. S. Krishnan, Journal of Energy Technologies and Policy 2, $42-53$ (2012).

15. P. Lawrence, P. K. Mathews and B. Deepanraj, Journal of Scientific and Industrial Research 70, 789-794 (2011).

16. T. Hejwowski, Vacuum 80, 1386-1390 (2006). 